\title{
O letramento, os multiletramentos e as mediações metodológicas: três aspectos das aprendizagens de leitura no trilho da BNCC
}

Maria Leoneide Rodrigues de Almeida ${ }^{1}$

Resumo: Com a BNCC, surge a necessidade de abordar os aspectos das aprendizagens de leitura, pois, embora o termo "letramento" seja bastante disseminado no ambiente escolar brasileiro e também entre os educadores, ainda é um tanto desconhecido pela maior parte das pessoas nas comunidades escolares, sobretudo agora com a nova dimensão de seu sentido com a inserção do termo "multiletramentos". O objetivo deste estudo é promover uma reflexão acerca das concepções de letramento e dos multiletramentos e do quanto as diversas abordagens metodológicas são mais significativas para a construção e o desenvolvimento desses processos. Foram apresentadas as convergências dessas concepções com as orientações da BNCC, quando esta discorre sobre os procedimentos de leitura como objeto do trabalho docente de todas as áreas de conhecimento. Para o alcance desse propósito, a opção metodológica foi buscar na literatura os aspectos conceituais que servissem de base para essa reflexão, fundamentados com dados de pesquisas. A expectativa é que se promova uma compreensão de que as práticas sociais da leitura e da escrita são complexas; logo, devem ser consideradas as situações diversas e adversas dos contextos e culturas, as mediações metodológicas mais significativas a partir da concepção de letramento e dos multiletramentos, para ultrapassar a maneira abstrata e universal com que os atores da Educação Básica tratam esses processos das aprendizagens de leitura em suas comunidades escolares.

Palavras-chave: BNCC. Letramento. Multiletramentos. Mediações metodológicas.

\section{Literacy, multi-literacy and methodological mediations: three aspects of learning to read on the BNCC trail}

Abstract: With the use of BNCC, there is a need to address aspects of learning to read, because, although the term literacy is widely disseminated in the Brazilian school environment and also among educators, it is still somewhat unknown to most people in school communities, today, even more with the new dimension of the meaning of this term with the insertion of the term "multiletramento" (multi aspects of literacy, multi-literacy). This study has the objective to promote a reflection on the concepts of literacy and "multi-literacy" and how much the different methodological approaches 
are more significant for the construction and development of these processes. We aimed to present the convergences of these concepts with the guidelines of the BNCC, once it discusses the reading procedures as the object of the teaching work in all areas of knowledge. To achieve this purpose, the methodological option was to seek, in the literature, the conceptual aspects that would serve as a basis for this reflection, based on research data. The expectation is to promote an understanding that the social practices of reading and writing are complex, therefore one must consider the diverse and adverse situations of contexts and cultures, the most significant methodological mediations from the conception of literacy and "multi-literacy", in order to overcome the abstract and universal way in which basic education actors treat these processes of learning to read in their school communities.

Keywords: BNCC. Literacy. Multi aspects of literacy. Methodological mediations.

\section{Alfabetización, multi-alfabetización y mediaciones metodológicas: tres aspectos del aprendizaje a leer en el camino de la BNCC}

Resumen: Con la BNCC, es necesario abordar aspectos del aprendizaje de la lectura porque, aunque el término alfabetización (en la dimensión de la práctica social de la lectura y la escritura) está bastante extendido en el entorno escolar brasileño y también entre los educadores, todavía es algo desconocido para la mayoría de las personas en las comunidades escolares, hoy, aún más con la nueva dimensión del significado de ese término con la inserción del término "multi-alfabetización" (múltiples aspectos de la práctica social de lectura y escritura). El objetivo es promover una reflexión sobre los conceptos de alfabetización y "multi-alfabetización" y cuánto los diferentes enfoques metodológicos son más significativos para la construcción y el desarrollo de estos procesos. Intentamos presentar las convergencias de estos conceptos con las pautas del BNCC, cuando discute los procedimientos de lectura como objeto del trabajo de la enseñanza en todas las áreas del conocimiento. Para lograr este propósito, la opción metodológica era buscar, en la literatura, los aspectos conceptuales que servirían de base para esta reflexión, con base en datos de investigación. La expectativa es promover la comprensión de que las prácticas sociales de lectura y escritura son complejas, por lo que se deben considerar situaciones diversas y adversas de los contextos y culturas, las mediaciones metodológicas más significativas desde la concepción de la alfabetización y "multi-alfabetización", para superar la forma abstracta y universal en que los actores de educación básica tratan estos procesos de aprendizaje de la lectura en sus comunidades escolares.

Palabras clave: BNCC. Alfabetización. Herramientas múltiples. Mediaciones metodológicas.

\section{Tempo de mudanças na Educação Básica}

O Brasil se encontra em um tempo de mudanças inéditas na Educação Básica, impostas pelas exigências deste século XXI. Chega-se à segunda década desse século com novas configurações das relações social, econômica, política, profissional e tecnológica, que têm acontecido em nível tão profundo que a 
quebra de sólidos paradigmas tem impactado diretamente a área da educação. Esse cenário exige que a escola assuma um novo papel no processo de formação e desenvolvimento da pessoa, a fim de possibilitar ao estudante vivências de construção de conhecimentos que deverão ser mais significativos para assegurar que o que foi aprendido seja útil e capaz de ultrapassar os espaços da escola e alcançar aplicação na vida.

Fica evidente que todos esses aspectos compõem uma realidade que gera inquietações, dúvidas e inseguranças e, por essa razão, impõe a condição de reconhecer a necessidade de se falar sobre essa nova forma de se fazer educação no Brasil. E uma indagação surge naturalmente: por onde começar? A expectativa é que a Base Nacional Comum Curricular (BNCC), por ser o documento legal de principal referência, que vai institucionalizar as mudanças em todo o sistema educacional brasileiro, pautado nos fundamentos da educação integral do estudante e do desenvolvimento de competências cognitivas e socioemocionais, seja o suporte que, efetivamente, orientará para que se alcancem os anseios de uma reforma qualitativa da educação brasileira.

Todo esse contexto foi tomado como mote para a escolha do objeto de estudo deste artigo: as competências de letramento e multiletramentos. São termos que incluem, por essência, a necessidade de se percorrer também o trilho das mediações metodológicas. Será tratada dessa temática na perspectiva de agregar uma reflexão oportuna, que possibilite o despertar de uma consciência docente, no que se refere à responsabilidade pelas aprendizagens, aspecto fundamentado na BNCC, que se torna um desafio muito maior que o da responsabilidade pelo ensino, praticado até hoje no sistema de educação brasileira.

Considera-se plausível e consistente a escolha do objeto deste estudo, porque, embora letramento seja um termo já bastante disseminado no ambiente escolar e acadêmico brasileiro e também entre os educadores, ainda é um tanto desconhecido pela maior parte das pessoas, não só das comunidades escolares, mas também da população como um todo, principalmente quando se constata uma nova dimensão de seu sentido com a inserção do termo "multiletramentos".

No campo deste estudo, intenciona-se abordar que esses termos, na verdade, procuram compreender a leitura e a escrita como práticas sociais complexas, imbricadas nas competências de compreensão e de aplicação dos conhecimentos apreendidos e aprendidos, considerando as situações diversas e adversas, bem como suas dimensões políticas e implicações ideológicas e sociais. Faz-se mister salientar o quanto é necessária a abordagem da concepção do letramento e dos multiletramentos no contexto específico da Educação Básica, para se ultrapassar a maneira abstrata e universal com que os atores de todas as etapas desse período escolar tratam em suas comunidades escolares. 
Kuenzer (2008, p. 37-38), considerando os aspectos característicos da sociedade, ainda no início do século XXI, no que se refere à profissionalização, declarou:

Estamos em novos tempos. [...] O novo discurso refere-se a um trabalhador de novo tipo, para todos os setores da economia, com capacidades intelectuais que lhe permita adaptar-se à produção flexível. Dentre elas, algumas merecem destaques: a capacidade de comunicar-se adequadamente, por intermédio do domínio dos códigos e linguagens, incorporando, além da língua portuguesa, a língua estrangeira e as novas formas trazidas pela semiótica; a autonomia intelectual para promover problemas práticos utilizando os conhecimentos científicos, buscando aperfeiçoar-se continuamente; a autonomia moral, por meio da capacidade de enfrentar novas situações que exige posicionamento ético; finalmente a capacidade de comprometer-se com o trabalho, entendido em sua forma mais ampla de construção do homem e da sociedade, por meio da responsabilidade, da crítica, da criatividade.

$\mathrm{E}$, nesse contexto, as habilidades de letramento e de multiletramentos, em todas as áreas, passam a ser estratégicas para a avaliação crítica, a participação produtiva, as relações interpessoais em casa, na escola e em sociedade, a participação social e política, em todas as etapas da Educação Básica, uma vez que:

as crianças estão vivendo mudanças importantes em seu processo de desenvolvimento que repercutem em suas relações consigo mesmas, com os outros e com o mundo. [...] a progressão do conhecimento ocorre pela consolidação das aprendizagens anteriores e pela ampliação das práticas de linguagem e da experiência estética e intercultural das crianças, considerando tanto seus interesses e suas expectativas quanto o que ainda precisam aprender (BRASIL, 2018, p. 58).

O objetivo deste artigo é, pois, promover uma reflexão acerca das concepções de letramento e dos multiletramentos e do quanto as diversas abordagens metodológicas são mais significativas para a construção e o desenvolvimento desses processos. Por essa razão, foram apresentadas as convergências dessas concepções com as orientações da BNCC, quando esta discorre sobre os procedimentos de leitura como objeto do trabalho docente de todas as áreas de conhecimento. Dessa forma, para o alcance desse propósito, a opção metodológica foi buscar na literatura aspectos conceituais que servissem de base para essa reflexão, fundamentados com dados de pesquisas acerca da temática em discussão.

E, pensando na possibilidade de este estudo servir para lançar mesmo que uma pequena luz sobre a complexidade desse novo cenário da Educação Básica no Brasil, acredita-se em sua relevância por trazer fundamentos que possibilitarão um repensar do fazer pedagógico a partir das concepções de letramento e 
multiletramentos. E que, com a compreensão dessas concepções, haja um direcionamento dessa reflexão para um repensar de ações docentes que priorizem o jovem e suas perspectivas de vida, que respeitem seus direitos de aprender conforme seus contextos e suas exigências multiculturais. Por conseguinte, que essas ações contribuam, efetivamente, para o desenvolvimento de competências para os multiletramentos e reverberem no desenvolvimento do estudante, alcançando, de forma integral, a sua formação cognitiva, emocional e social.

\section{Letramento e multiletramentos: perspectivas imprescindíveis aos novos desafios}

Para fundamentar o que se propõe neste artigo, discorrer-se-á sobre os pontos preponderantes à temática pesquisada, primeiro no que tange à concepção de letramento, incluindo conceitos e definições de leitura, depois no que diz respeito aos multiletramentos, suas características e suas implicações para os contextos da prática pedagógica.

Busca-se esclarecer a capacidade de compreensão daquilo que se lê, considerando a multiplicidade dos processos cognitivos em que está inserida a pessoa, a importância da participação do outro quando se vivenciam procedimentos mentais imprescindíveis à leitura e à produção escrita, haja vista essa ser uma questão dialógica como princípio do ato de ler, que é uma experiência individual e interpessoal profunda e que está conectada com conhecimentos prévios, com as "leituras de mundo" e com todo o potencial metodológico.

A abordagem do que apresenta a literatura será tratada em alinhamento com as orientações da BNCC, com o intuito de ratificar a importância e a urgência em se rever, repensar e refazer práticas pedagógicas ineficazes, estabelecidas sem qualquer vínculo com as diversas leituras da realidade do estudante do século XXI.

\section{O percurso inicial da condição e dos processos de letramento}

Uma pessoa é inserida no universo da escrita, primeiramente, pelo processo de alfabetização, que é o meio de aquisição de uma tecnologia; depois, por meio do desenvolvimento de competências (habilidades, conhecimentos, atitudes) de uso efetivo dessa tecnologia em práticas sociais que envolvem a língua escrita - a isso, dá-se o nome de letramento (SOARES, 2003). A autora aprofunda essa teoria quando esclarece que:

Antes do surgimento da palavra, e ainda hoje, usava-se/usa-se apenas a palavra alfabetização para referir-se à inserção do indivíduo no mundo da escrita, tornando-se sempre necessário, neste caso, expli- 
citar que por "alfabetização" não se estava/está entendendo apenas a aquisição da tecnologia da escrita, mas, mais amplamente, a formação do cidadão leitor e escritor. O uso da palavra vem distinguir os dois processos, por um lado garantindo a especificidade do processo de aquisição da tecnologia da escrita, por outro lado atribuindo não só especificidade, mas também visibilidade ao processo de desenvolvimento de habilidades e atitudes de uso dessa tecnologia em práticas sociais que envolvem a língua escrita (SOARES, 2003, p. 91).

A distinção desses termos é útil para os programas de inserção de indivíduos no mundo da escrita, sobretudo em países que ainda enfrentam altos índices de analfabetismo, como é o caso do Brasil; não seria, pois, tão necessária essa distinção em países em que, praticamente, não há existência de analfabetos. $\mathrm{Na}$ literatura de língua inglesa, uma única palavra, literacy, designa o processo de inserção no mundo da escrita, referindo-se tanto à aquisição da tecnologia quanto ao seu uso competente nas práticas sociais de leitura e de escrita (SOARES, 2003).

Soares (2003), citando Street (1995), ainda afirma que o termo "letramento" pode ser denominado como o exercício efetivo e competente da tecnologia da escrita, que implica habilidades várias, tais como:

capacidade de ler ou escrever para atingir diferentes objetivos - para informar ou informar-se, para interagir com outros, para imergir no imaginário, no estético, para ampliar conhecimentos, para seduzir ou induzir, para divertir-se, para orientar-se, para apoio à memória, para catarse [...]; habilidades de interpretar e produzir diferentes tipos de gêneros de textos; habilidades de orientar-se pelos protocolos de leitura que marcam um texto ou de lançar mão desses protocolos, ao escrever; atitudes de inserção efetiva no mundo da escrita, tendo interesse e prazer em ler e escrever, sabendo utilizar a escrita para encontrar ou fornecer informações e conhecimentos, escrevendo ou lendo de forma diferenciada, segundo as circunstâncias, os objetivos, o interlocutor [...] (SOARES, 2003, p. 91).

Ao encontro de Soares, Britto (2003) também aponta que o termo foi introduzido no Brasil como resultado da versão do termo "literacy", o qual tradicionalmente era traduzido por alfabetização. O conceito de alfabetização na sociedade contemporânea passou por novas compreensões, particularmente, nos países de primeiro mundo, nos quais a universalização da Educação Básica já ocorrera há pelo menos meio século. E foi por causa disso e do desenvolvimento de pesquisas sobre a escrita que a referida palavra inglesa recebeu nova tradução. Pode-se dizer, portanto, que a formulação e a aplicação desse novo conceito resultaram de necessidades teóricas e várias práticas, em função dos avanços no modo de compreender as relações inter-humanas, dos processos de participação social e do acesso às informações e à construção de conhecimentos. 
Enquanto o termo, em sua concepção primeira, diz respeito ao alfabetismo, à alfabetização e à cultura escrita, em seu novo contexto, considerando o aspecto morfoconceitual, pode-se enfocá-lo a partir do valor semântico do sufixo -mento, cujas possibilidades de interpretação, ainda conforme Britto (2003), são de "estado/condição" e "processo/ação". Como estado ou condição, visualiza-se firmamento; como processo e ação, vê-se indiciamento; processo/ação e estado/ condição estão diretamente entrelaçados e um remete ao outro, segundo o autor.

Entretanto, há uma diferença conceitual e prática muito importante: 1) letramento como processo diz respeito a políticas educacionais e culturais, metodologias de ensino e seleção de conteúdos, ou seja, são processos pelos quais uma sociedade estabelece a distribuição dos saberes, ou ações político-sociais e pedagógicas de formação dos sujeitos na cultura escrita; 2) letramento como condição diz respeito à capacidade objetiva de uma pessoa ou um grupo social, ou seja, é a condição em que se encontram indivíduos ou grupos sociais e que lhes permite utilizar as competências de ler e escrever para atuar nos espaços sociais organizados em função da escrita. Em suma, condição de letramento está para competência e habilidade, assim como processo do letramento está para escolarização e alfabetização.

Para Britto (2003, p. 53), ainda com relação à interpretação de letramento enquanto processo, há outros dois aspectos a considerar:

O primeiro é que esse processo pode estar subordinado às agências institucionais (por exemplo, a escola) como ocorrer em função de ações mais difusas, ainda que não menos significativas (mídia, imprensa, indústria do entretenimento, serviços públicos etc.). $\mathrm{O}$ segundo é, diferentemente de alfabetização, cujo sentido mais frequente está associado ao ensino-aprendizagem do sistema de escrita (que, no caso das línguas ocidentais, é alfabético), letramento remeteria para um movimento mais geral, que se relaciona com a percepção da ordem e da escrita, de seus usos e objetos, bem como de ações que uma pessoa ou um grupo de pessoas faz com base em conhecimentos e artefatos da cultura escrita. Sendo assim, se a noção de alfabetizado implica uma condição do tipo tudo ou nada, a de letramento (ou de alfabetismo) sugere uma multiplicidade de níveis e graus, em função do quanto o indivíduo realiza com seus conhecimentos de escrita.

Em seu livro intitulado "Letramento, um tema em três gêneros", que, segundo alguns autores e pesquisadores do assunto, foi um dos que mais contribui para a divulgação do conceito, Soares (2003, p. 18) afirma que:

letramento é o estado ou a condição que adquire um grupo social ou um indivíduo como consequência de ter-se apropriado da escrita. [...] O sujeito letrado é aquele que, além de saber ler e escrever, 
sabe também fazer uso do ler e escrever, sabe responder às exigências de leitura e de escrita que a sociedade faz continuamente.

Ribeiro (2003) defende que a incorporação desse conceito pela educação escolar justifica-se, simplesmente, pelo aumento da percepção de que o conhecimento e o uso da escrita possibilitam modificações significativas e importantes na vida das pessoas e que esse fato implica não só o domínio mecânico do sistema, mas também a capacidade de manipular, de forma ativa, discursos e referenciais culturais. No entanto, se o indivíduo letrado tem, em sua vida, alguns referenciais ímpares, a incorporação do conceito de letramento pela escola redefine, no espaço da aula, a atribuição de responsabilidades. Isso pode dar um novo significado ao próprio conceito de ensino não da área de linguagens, mas de todas as áreas de conhecimento, em função dos valores, objetivos e conteúdos de ensino que serão redefinidos. Assim, torna-se inevitável a interdisciplinaridade estrita que supõe o ensino da leitura e da escrita, independentemente da área e da etapa de atuação docente.

Com a compreensão desse conceito, professores avançam na capacidade de redirecionar suas ações pedagógicas, com maior consciência didática, para contribuir para o desenvolvimento dos seus alunos, tornando-os capazes de "sobreviver" bem aos desafios de leitura em que são necessárias atitudes e postura de interpretação. Assim, o termo "analfabeto funcional" passaria a não ser usado com tanta frequência nas escolas - e muitas vezes até inadequadamente.

Infante (1994 apud RIBEIRO, 2003) define o termo "analfabeto funcional" como o indivíduo incapaz de todas as atividades em que a alfabetização é requerida para uma atuação eficaz em seu grupo e comunidade. O fato é que, mesmo sabendo ler e escrever algo simples, a pessoa não tem habilidades - ou tem domínio bem limitado - de leitura, escrita e cálculo, necessários para viabilizar o seu desenvolvimento pessoal e profissional. O "não analfabeto funcional" teria, então, a possibilidade de continuar usando a leitura, a escrita e o cálculo a serviço de seu próprio desenvolvimento e do desenvolvimento de sua comunidade.

Nesse contexto, um ponto crítico que merece atenção diz respeito às condições em que se podem estabelecer relações entre o letramento e as características psicológicas de indivíduos ou grupos sem cair nas armadilhas de um determinismo muito estreito, de acordo com Ribeiro (1998), que também declara:

No campo das teorias do alfabetismo, já foi amplamente reconhecida a impropriedade da postulação de que a disseminação da linguagem escrita em si constitui o divisor de águas entre culturas tradicionais e modernas, ou ainda, no plano psicológico, que a aprendizagem da leitura e escrita por si só possa produzir mudanças psicológicas tais como desenvolvimento do pensamento categorial ou ainda atitudes modernizantes (RIBEIRO, 1996, p. 6). 
Como afirma Olson, em seu artigo "Cultura escrita e oralidade" (1995 apud RIBEIRO, 2003), não importa o que a linguagem escrita faz, mas sim o que é possível fazer com ela, ou seja, como é utilizada em práticas e contextos específicos e que recursos culturais ela põe à disposição.

Levando em conta esse aspecto "de liberdade" para se ter atitude, a partir da habilidade de letramento, é importante considerar o quanto é recíproca a relação entre as habilidades de leitura e escrita e as atitudes que o indivíduo pode ter. Se, de um lado, um indivíduo com habilidade de leitura e escrita consegue se dedicar a determinadas atividades ou se sente inclinado a atuar com certo direcionamento diante de uma situação-desafio, por outro lado, essas atividades ou inclinações podem criar as oportunidades de que suas habilidades de leitura e escrita se desenvolvam em um sentido determinado. Ou seja, um indivíduo letrado consegue ter atitude para vivenciar situações-problema e resolvê-las, ao mesmo tempo que certas vivências contribuirão para que se consolidem suas habilidades de leitura e escrita.

E o que dizer dessa liberdade sendo ampliada pelo fenômeno do surgimento de inúmeros gêneros, meios e recursos de leitura e escrita? Se "sobreviver bem" diante de desafios de leitura e escrita consiste em uma concepção mais sustentada de letramento, ainda é preciso apropriar-se dos elementos que caracterizam os multiletramentos, os quais serão tratados neste próximo tópico.

\section{Do letramento aos multiletramentos: o percurso das linguagens múltiplas e das novas exigências de mediação}

Com o advento das novas tecnologias, cada vez mais inovadoras, tem-se acompanhado o surgimento das múltiplas modalidades e gêneros textuais, com estruturas e recursos que requerem habilidades mais evoluídas e até de sofisticação linguística de codificação e decodificação, tanto dos leitores quanto dos produtores. Eles exigem capacidades de acessar, selecionar, compreender, posicionar e articular as informações, afirma Rodrigues (2016), que citou, também, esta colocação da professora chilena, colaboradora da UNICAMP:

Tecnologias como a televisão, o cinema, o rádio e o computador não têm usurpado o lugar privilegiado da palavra escrita; pelo contrário, eles aumentaram as demandas de leitura feitas aos cidadãos para se integrarem na sociedade contemporânea, pois o indivíduo que pode fazer uso de todas as vantagens de uma tecnologia como o computador, por exemplo, é aquele indivíduo que é leitor (e que escreve) (KLEIMAN; MORAES, 1999, p. 92 apud RODRIGUES, 2016, p. 4).

Nesse contexto, insere-se o termo "multiletramentos", cuja origem histórica do conceito procura cobrir dois "multi": a multiculturalidade, característica das 
sociedades globalizadas, e a multimodalidade dos textos, por meio dos quais a multiculturalidade se comunica e informa (ROJO, 2012). Nas palavras dessa autora, a concepção de multiletramentos apresenta-se com as seguintes características:

Diferentemente do conceito de letramentos (múltiplos), que não faz senão apontar para a multiplicidade e variedade das práticas letradas, valorizadas ou não, nas sociedades em geral, o conceito de multiletramentos - é bom enfatizar - aponta para dois tipos específicos e importantes de multiplicidade presentes em nossas sociedades, principalmente urbanas, na contemporaneidade: a multiplicidade cultural das populações e a multiplicidade semiótica de constituição dos textos por meio dos quais ela se informa e se comunica (ROJO, 2012, p. 12-13).

Há um aspecto diretamente ligado a essas perspectivas teóricas que representa um dos maiores desafios a se superar: as práticas de ensino. Para alinhar-se não só a essas concepções teóricas, mas também a orientações da BNCC, em vez de se manter o foco nas formas de ensinar, deve-se dar espaço às formas de aprender, ou seja, a centralidade, agora, deve ser nas práticas de aprendizagem, que precisam contemplar as múltiplas culturas que os estudantes trazem e que se manifestam por meio de diversas linguagens. Por essa razão, colocar as diversas linguagens em diálogo com os tipos de manifestação cultural é uma forma de ampliar o universo cultural dos estudantes e de ajudá-los a atribuir sentido ao que a escola lhe ensina.

Ainda no que se refere à multiplicidade de culturas, Rojo (2012, p. 14) afirma que "vivemos, já pelo menos desde o início do século XX (senão desde sempre), em sociedades de híbridos impuros, fronteiriços". E complementa citando García Canclini (2008 apud ROJO, 2012, p. 12):

O que hoje vemos à nossa volta são produções culturais letradas em efetiva circulação social, como um conjunto de textos híbridos de diferentes letramentos (vernaculares e dominantes), de diferentes campos (ditos "popular/de massa/erudito"), desde sempre, híbridos, caracterizados por um processo de escolha pessoal e política e de hibridização de produções de diferentes "coleções".

Fica evidente, então, a necessidade de inclusão nas práticas escolares de diversos gêneros textuais, porque é essa diversidade que faz parte do cotidiano dos estudantes. Assim, igualmente importante é a clareza docente no propósito de prepará-los, com o desenvolvimento de habilidades e competências que os tornem capazes de lidar com o mundo contemporâneo multiletrado e com condições de atender às demandas em relação à leitura, à escrita e à diversidade cultural, provenientes do surgimento e expansão das tecnologias digitais (RODRIGUES, 2016). 
Ou seja, do letramento aos multiletramentos, o cerne da questão se encontra nos procedimentos de leitura. O início dessas duas habilidades passa pela aptidão do leitor. Ler é uma atividade complexa, por levar o leitor a produzir inferências a partir das informações captadas no texto, dos conhecimentos que já possui e de suposições. Entender é, essencialmente, uma atividade de relacionar conhecimentos, experiências e ações em um movimento interativo e negociado. Uma leitura eficaz exige o esforço de entender e construir uma interpretação, o qual consiste, primeiramente, na ativação do conhecimento prévio, que envolve os conhecimentos linguístico, textual e enciclopédico. O conhecimento linguístico é implícito, não verbalizado, que abrange desde o conhecimento do vocabulário até o uso da língua; já o conhecimento textual é o conjunto de noções e conceitos que o leitor tem sobre o texto; e o conhecimento de mundo ou enciclopédico é adquirido por meio das experiências e do convívio social (BORTONI-RICARDO et al., 2012).

Diante dessas concepções, em todas as áreas, parece que se está fazendo parte de uma conjuntura político-social de constantes desafios, mas, para a área de educação no Brasil, esses desafios têm sido cada vez mais complexos e de proporção bem preocupante. As referências a esse cenário revelam evidências que comprovam o quão lentas são as respostas das ações para a superação desse perfil fragmentado e inconsistente de letramento do estudante brasileiro, mesmo que algumas pesquisas apontem aspectos tímidos de avanços.

As evidências dos exames externos de larga escala, por exemplo, a cada ano, têm demonstrado o quanto os estudantes ainda apresentam muitas dificuldades de dominar as habilidades de letramento básico. Outros estudos corroboram esses fatos. A organização não governamental Ação Educativa e o Instituto Paulo Montenegro desenvolveram o Indicador de Alfabetismo Funcional $(\mathrm{INAF})^{2}$, que vem realizando estudos desde 2001 para medir os níveis de alfabetismo da população brasileira que tem entre 15 e 64 anos.

Em 2018, a pesquisa apontou que 7 entre 10 brasileiros desse público podem ser considerados funcionalmente alfabetizados. Isso significa que em torno de 30\% dos concluintes da Educação Básica apresentam desempenho inferior às expectativas inerentes a todo um processo escolar. As instituições registram que, ao analisar os níveis de alfabetismo no país, o INAF busca contribuir para a defesa dos direitos educativos dos brasileiros, incidindo na agenda acerca do desenvolvimento educacional do país. Assim, coloca em debate o próprio significado de analfabetismo, que não pode se restringir a uma visão binária de alfabetizado versus não alfabetizado, e sim de um processo gradativo de aquisição e consolidação de habilidades.

Outro dado importante é o da leitura per capita no Brasil. Por aqui, leem-se em torno de 4,96 livros por ano, quando, em países desenvolvidos, essa média é de 7 livros/ano, como na França. O percentual de 5,1 se refere aos Estados 
Unidos, e o de 4,9, à Inglaterra. Essa mesma pesquisa, realizada pelo Instituto Pró-livros, em 2016, intitulada "Retratos da Leitura", apontou que 56\% das pessoas acima de 5 anos de idade se enquadram como leitores regulares (aqueles que leem, pelo menos, partes de um livro a cada três meses).

Esses números, que revelam apenas um aspecto da educação brasileira, reafirmam a urgência de uma intervenção política educacional, desafio esse que a BNCC pode representar uma possibilidade de avanços, porque se fundamenta na aprendizagem significativa e coloca o professor como mediador das aprendizagens e dos processos de construção de conhecimento. Tanto que o documento reitera o movimento metodológico de documentos curriculares anteriores, registrando que:

estudos de natureza teórica e metalinguística - sobre a língua, sobre a literatura, sobre a norma padrão e outras variedades da língua - não devem nesse nível de ensino ser tomados como um fim em si mesmo, devendo estar envolvidos em práticas de reflexão que permitam aos estudantes ampliarem suas capacidades de uso da língua/linguagens (em leitura e em produção) em práticas situadas de linguagem [...]. (BRASIL, 2018, p. 71).

E considera esse conjunto de princípios e pressupostos para firmar os eixos de integração do componente Língua Portuguesa, já consagrados nos documentos curriculares da área de Linguagens, que correspondem às

práticas de linguagem: oralidade, leitura/escuta, produção (escrita e multissemiótica) e análise linguística/semiótica (que envolve conhecimentos linguísticos - sobre o sistema de escrita, o sistema da língua e a norma-padrão -, textuais, discursivos e sobre os modos de organização e os elementos de outras semioses) (BRASIL, 2018, p.71).

Para o trabalho com as práticas de linguagem - leitura de textos, produção de textos, oralidade e análise linguística/semiótica -, a BNCC propõe uma organização do currículo, articulando-as com os campos de atuação em que essas práticas se realizam, e "aponta para a importância da contextualização do conhecimento escolar, para a ideia de que essas práticas derivam de situações da vida social e, ao mesmo tempo, precisam ser situadas em contextos significativos para os estudantes" (BRASIL, 2018, p. 84). E classifica em cinco esses campos de atuação (BRASIL, 2018, p. 84):

Campo da vida cotidiana (somente anos iniciais), Campo artístico-literário, Campo das práticas de estudo e pesquisa, Campo jornalístico-midiático e Campo de atuação na vida pública, sendo que esses dois últimos aparecem fundidos nos anos iniciais do Ensino Fundamental, com a denominação Campo da vida pública: 


\begin{tabular}{|l|l|}
\hline Anos iniciais & Anos finais \\
\hline Campo da vida cotidiana & Campo artístico-literário \\
\hline Campo artístico-literário & $\begin{array}{l}\text { Campo das práticas de estudo } \\
\text { e pesquisa }\end{array}$ \\
\hline $\begin{array}{l}\text { Campo das práticas de estudo } \\
\text { e pesquisa }\end{array}$ & Campo jornalístico-midiático \\
\hline Campos da vida pública & $\begin{array}{l}\text { Campo de atuação na vida } \\
\text { pública }\end{array}$ \\
\hline
\end{tabular}

No que diz respeito ao eixo leitura, cabe enfatizar que a BNCC:

compreende as práticas de linguagem que decorrem da interação ativa do leitor/ouvinte/espectador com os textos escritos, orais e multissemióticos e de sua interpretação, sendo exemplos as leituras para: fruição estética de textos e obras literárias; pesquisa e embasamento de trabalhos escolares e acadêmicos; realização de procedimentos; conhecimento, discussão e debate sobre temas sociais relevantes; sustentar a reivindicação de algo no contexto de atuação da vida pública; ter mais conhecimento que permita o desenvolvimento de projetos pessoais, dentre outras possibilidades (BRASIL, 2018, p. 71).

\section{Registra-se também que, no contexto do referido documento,}

leitura é tomada em um sentido mais amplo, dizendo respeito não somente ao texto escrito, mas também a imagens estáticas (foto, pintura, desenho, esquema, gráfico, diagrama) ou em movimento (filmes, vídeos etc.) e ao som (música), que acompanha e cossignifica em muitos gêneros digitais (BRASIL, 2018, p. 72).

Para o tratamento das práticas leitoras, o documento orienta ainda que o trabalho deve ser desenvolvido a partir da compreensão de sete dimensões inter-relacionadas às práticas de uso e reflexão, que se apresentam assim:

1- Reconstrução e reflexão sobre as condições de produção e recepção dos textos pertencentes a diferentes gêneros e que circulam nas diferentes mídias e esferas/campos de atividade humana.

2- Dialogia e relação entre textos.

3- Reconstrução da textualidade, recuperação e análise da organização textual, da progressão temática e estabelecimento de relações entre as partes do texto.

4- Reflexão crítica sobre as temáticas tratadas e validade das informações. 
5- Compreensão dos efeitos de sentido provocados pelos usos de recursos linguísticos e multissemióticos em textos pertencentes a gêneros diversos.

6- Estratégias e procedimentos de leitura.

7- Adesão às práticas de leitura (BRASIL, 2018, p. 72-74).

Ou seja, a BNCC estabelece uma proposta de trabalho com centralidade no texto, de modo a se considerar as:

perspectivas enunciativo-discursivas na abordagem, sempre relacionando os textos a seus contextos de produção e o desenvolvimento de habilidades ao uso significativo da linguagem em atividades de leitura, escuta e produção de textos em várias mídias e semioses (BRASIL, 2018, p. 67).

Orienta que o aumento das demandas cognitivas das atividades de leitura deve ser progressivo, desde os anos iniciais do Ensino Fundamental até o Ensino Médio. Além disso, estabelece os campos de atuação para as práticas de linguagem situadas, corroborando "a importância da contextualização do conhecimento escolar, para a ideia de que essas práticas derivam de situações da vida social e, ao mesmo tempo, precisam ser situadas em contextos significativos para os estudantes" (BRASIL, 2018, p. 84).

Assim, a nova perspectiva para o trabalho com a linguagem consiste em

proporcionar aos estudantes experiências que contribuam para a ampliação dos letramentos, de forma a possibilitar a participação significativa e crítica nas diversas práticas sociais permeadas/ constituídas pela oralidade, pela escrita e por outras linguagens (BRASIL, 2018, p. 67-68).

A BNCC determina, por lei, a garantia dos direitos de aprendizagem dos estudantes, que devem desenvolver habilidades e competências, a fim de se tornarem protagonistas de suas aprendizagens, nas quais está o foco de toda a prática pedagógica, e não mais no ensino. Há o propósito de superação da fragmentação radicalmente disciplinar do conhecimento para abrir espaço à valorização dos contextos e ressignificar o que se aprende. Trata-se de se estimular a aplicação dos conhecimentos escolares na vida real, o que contribuirá para o protagonismo do estudante em sua aprendizagem e na construção de seu projeto de vida (BRASIL, 2018).

Nesse aspecto, constatam-se novas exigências de mediação docente. $\mathrm{O}$ documento orienta que a prática pedagógica possibilite uma formação para o desenvolvimento humano global e expressa a compreensão da complexidade desse desenvolvimento, quando apresenta a "visão plural, singular e integral do educando, considerando-os como sujeitos de aprendizagem e rompendo com as 
visões reducionistas que privilegiam ou a dimensão intelectual (cognitiva) ou a dimensão afetiva” (BRASIL, 2018, p. 12). Sobre a proposta pedagógica para uma educação integral, não se limita à ampliação de tempo e espaço e orienta a construção de diversas oportunidades e situações de aprendizagem que enfoquem a transformação integral da pessoa.

Dessa forma, o compromisso da escola deve estar articulado com todos os sujeitos envolvidos, além de gerar cumplicidade e envolvimento na conquista da produção desses saberes. Para isso, deve garantir a possibilidade de processos de construção de novas aprendizagens por meio da interdisciplinaridade e da prática da contextualização, primando sempre por aquilo que é significativo.

Ao encontro das orientações da BNCC, vem a pedagogia dos multiletramentos, que:

tem uma visão de mente, sociedade e aprendizagem baseada na suposição de que a mente humana é incorporada, situada e social. Ou seja, de que o conhecimento humano é embutido em contextos sociais, culturais e materiais e seu conhecimento desenvolvido como parte de um processo de interações colaborativas com outros de diferentes habilidades, contextos e perspectivas que fazem parte de uma mesma comunidade (COPE; KALANTZIS, 2000, apud SILVA, 2016, p. 12).

O fato é que o mundo contemporâneo é caracterizado pela multiplicidade cultural que se expressa e se comunica por meio de textos multissemióticos (impressos ou digitais), ou seja, textos que se constituem por meio de uma multiplicidade de linguagens (fotos, vídeos e gráficos, linguagem verbal oral ou escrita, sonoridades) que fazem significar esses textos. Essa "multimodalidade, multissemiose ou multiplicidade de linguagens exige capacidades e práticas de compreensão e produção de cada uma delas (multiletramentos) para fazer significar" (ROJO, 2012, p. 13). Em outras palavras: exige novos letramentos, novas práticas e habilidades: digital, visual, sonora. Ainda de acordo com a autora:

A Pedagogia dos Multiletramentos é necessária para transformar o aluno de consumidor acrítico em analista crítico. Para que a escola possibilite aos alunos participar de práticas sociais de leitura e escrita, de forma ética, crítica e democrática é preciso levar em conta os multiletramentos e deixar de ignorar os letramentos locais, colocando-os em contato com aqueles que são valorizados pela sociedade. Também é preciso sair do método tradicional que contempla a palavra escrita e ampliar a noção de letramentos para o campo das outras linguagens, que estão cada vez mais presentes nos textos, devido aos avanços tecnológicos. Assim, pode-se levar os alunos a perceberem o trato ético dos discursos nos textos (ROJO, 2012, p. 12). 
Para que isso se efetive, são requeridas práticas situadas, instrução aberta, enquadramento crítico, prática transformada para tornar o aluno usuário funcional, criador de sentidos, analista crítico e transformador.

Uma pedagogia voltada para esse sentido deve partir de práticas que considerem os letramentos, as culturas de referência dos alunos, os gêneros conhecidos por eles e que trazem para dentro da escola e relacioná-los com outras culturas, outras esferas sociais (RODRIGUES, 2016, p. 2).

Rodrigues (2016, p. 2-3) aprofunda defendendo que:

A instrução aberta consiste em uma análise crítica e consciente das práticas dos alunos e dos demais processos de produção e recepção a fim de avaliar os seus modos de significação, suas representações, seus valores. Por meio desse enquadramento crítico, além de levar os alunos a compreender e produzir diferentes enunciados, de diversas culturas e linguagens, é possível fazê-los entender o pluralismo cultural de forma crítica, ética, respeitosa.

Portanto, para mediações metodológicas mais significativas, novas ferramentas e novas práticas educacionais são necessárias para que se possa atingir esse propósito. Para Rodrigues (2016, p. 3), "além dos instrumentos de escrita manual e impressa, os alunos precisam dominar tecnologias de áudio, vídeo, tratamento da imagem, edição e diagramação”. E defende que esse domínio não se refere apenas ao manuseio, mas também à compreensão. Não se trata de as escolas apenas ensinarem o uso das tecnologias; mais que isso, precisam tornar os materiais tecnológicos acessíveis aos alunos e direcioná-los para criar estratégias de acesso às informações e condições de darem sentido a elas. Deve-se levar o aluno a refletir e compreender a intenção da combinação de linguagens, uma vez que isso lhe oportuniza maiores condições de acesso e participação no mundo globalizado.

\section{O desafio das mediações para o "criador de sentidos": reflexão final}

O contexto da Educação Básica contemporânea está permeado de desafios, e a BNCC é o documento que os institucionalizará. Ressaltou-se, em várias situações apresentadas neste artigo, que superar a fragmentação do ensino não significa desenvolver habilidades e competências de forma genérica e descontextualizada, mas por meio da leitura em suas inúmeras formas. E, na leitura de textos, todos os gêneros que circulam nos diversos campos de atividade humana devem ser considerados como objeto de estudo. 
Por esse quadro tão inovador quanto complexo, considera-se relevante apresentar o pensamento de Kneller (1972, p. 43):

Para educarmos os homens de um modo sensato e esclarecido, convém saber no que queremos que eles se tornem quando os educamos. E para sabê-lo é necessário indagar para que vivem os homens - ou seja - investigar qual pode ser a finalidade da vida e o que ele deve ser. Portanto, devemos também inquirir sobre a natureza do mundo e os limites que este fixa para o que o homem possa saber e fazer.

Nessa perspectiva, as palavras de Bagno (2002) ratificam a reflexão apresentada neste artigo. Ele defende que nenhum projeto educacional pode se contentar simplesmente em ensinar a ler e a escrever, mas deve oferecer aos indivíduos condições de letramento para o desenvolvimento cada vez mais intenso e extenso das habilidades de escrita e leitura tanto dentro quanto fora da escola. Em tempo: ler e escrever aqui, neste contexto de pesquisa, pode ser entendido como a formação mínima necessária do estudante em todas as áreas de conhecimento.

Assim, à guisa de finalizar a reflexão da temática deste estudo, acredita-se que foram alcançados os objetivos propostos e delineados a partir do que se tem apresentado na literatura acerca das concepções de letramento, dos multiletramentos e das formas de mediação metodológica com foco nas aprendizagens dos estudantes.

É fato que há urgência em se reformular e apresentar à sociedade brasileira um projeto de educação que busque atender às exigências do século XXI, que possibilite um nível de envolvimento de todos os atores da educação e que traga, em seu bojo, propostas inovadoras, mas exequíveis.

O conteúdo desenvolvido da literatura consultada revela que há uma necessidade explícita de se alterar o paradigma da educação praticada, principalmente se for considerada a necessidade de que qualquer pessoa tem de garantir uma desenvoltura eficiente diante dos desafios que envolvem a leitura; mais ainda, se essa pessoa é um estudante da Educação Básica, ela tem, agora, assegurada pela lei da BNCC o direito de receber uma formação adequada, compatível com o seu desenvolvimento e, sobretudo, que essa formação recebida atenda aos seus interesses para a vida.

É oportuno resgatar a reflexão de que o ato de ler não consiste na mera decodificação e interpretação da rede infindável dos símbolos linguísticos. Ler representa interagir, provocando novas leituras, mediante as inter-relações ou intertextualidades entre autor, texto e leitor, além de um quarto elemento - o mediador dessa leitura. Para alcançar mudanças em todo esse processo, é imprescindível modificar o tratamento dispensado à prática da leitura. Urge que se fomentem ações pedagógicas nas escolas, voltadas para uma visão mais ho- 
lística, de cunho sociointeracionista, desvencilhando-se dos conceitos de ensino "puro", que ostentam o caráter de reprodução de conceitos e valores específicos, atribuídos às áreas isoladamente.

Faz-se necessário, pois, alterar esse caráter de estagnação conferido aos componentes curriculares específicos e excluir do processo de ensino e aprendizagem o status das práticas de leitura como instrumento específico da área de linguagem. A leitura está para toda possibilidade de construção de conhecimento, e os processos e procedimentos de leitura deverão constituir todos os componentes curriculares e todas as áreas de conhecimento.

Por essa razão, o que se propõe é uma verdadeira ruptura dos professores, bem como de todos os gestores de educação, não só (mas também) de ordem interna e externa. No segmento externo, cabe aos gestores oportunizar aos professores encontros de palestras, orientações e oficinas sobre letramento e multiletramentos.

Em situações assim, uma mudança exige rompimento consigo mesmo e com sua história. Não basta apenas os professores falarem de letramento, de multiletramentos ou do nível em que se encontram seus alunos. Eles precisam reinventar-se para conseguir transformar a prática cotidiana de sala de aula e de vida. Trata-se de um posicionamento diante do mundo e da história contada nesse jogo de interpretações. Os procedimentos pedagógicos, como objetivos, conteúdos, metodologias, estratégias e avaliação, não são neutros, mas envolvem opções políticas menos ou mais conscientes, as quais, por sua vez, apenas o discurso não consegue contemplar.

Chegou o momento de se somar forças. Haverá sempre o que, por que, para que, quando e como se lê nas ciências exatas, nas sociais, nas da natureza e nas de comunicação. Assim, o primeiro passo será formalizar, sistematicamente, encontros para reflexão e conscientização de todo o corpo docente da instituição, sem exceção, no que tange ao conceito de letramento, dos multiletramentos e das formas novas de mediação metodológicas para aprendizagens mais significativas. Buscar profissionais com conhecimento na área, com dados de pesquisas recentes sobre essa questão, principalmente no contexto da Educação Básica, para apresentar a real situação e, a partir daí, instigar uma profunda reflexão da realidade que se vive como professor, independentemente da área.

De acordo com o Relatório da Comissão Internacional sobre Educação para o Século XXI (DELORS, 2010), a educação deverá transmitir "saberes e saber-fazer”, de forma significativa, adaptando-os à civilização cognitiva, uma vez que se revelam as bases das competências do futuro. Visando atender a essa nova realidade, a educação deverá assumir um caráter de "educação ao longo da vida", devendo ser sistematizada, considerando os quatro pilares do conhecimento, a saber: 
Aprender a aprender, associando uma cultura geral com a possibilidade de trabalhar em profundidade um pequeno número de matérias;

Aprender a fazer, a fim de adquirir não apenas uma qualificação profissional, mas obtendo competências que tornem o indivíduo apto a enfrentar situações adversas;

Aprender a viver juntos, desenvolvendo a percepção do outro e a compreensão das interdependências, preparando-se para gerir conflitos, no que se refere aos valores do pluralismo e da paz;

Aprender a ser, para melhor desenvolver a própria personalidade, situando-se à altura de agir cada vez mais com autonomia, discernimento e responsabilidade pessoal. Para isso, não deverá ser negligenciado pela educação nenhuma das potencialidades inerentes a cada indivíduo: memória, raciocínio, sentido estético, capacidades físicas e aptidão para comunicar-se através da linguagem (DELORS, 2010, p. 31).

Gadotti (2000), ao partilhar desse ideário, situa o papel do professor no futuro como um mediador do conhecimento, um sistematizador do trabalho no espaço escolar, em que o aluno deverá ser o centro do processo educativo, o sujeito de sua própria aprendizagem, necessitando, portanto, de aprender a aprender.

Nesse sentido, na visão do autor, na aprendizagem do futuro, é preciso conscientizar professor e aluno de que não basta reter conhecimentos, mas pensar conhecimentos reais, uma vez que a escola atua como o grande espaço de gestão do conhecimento, e o mundo, o maior livro de leitura do estudante.

Finalmente, reitera-se a convicção de que este estudo cumpriu seu propósito de possibilitar uma reflexão oportuna e importante sobre a temática e de fornecer suporte, embora tênue, à noção dos conceitos de letramento e de multiletramentos e do quanto é imprescindível a centralidade da prática pedagógica em novas mediações metodológicas, híbridas e inovadoras. A expectativa final é a de que as reflexões suscitadas no decorrer deste artigo possam abrir espaço para o aprofundamento do assunto; mais que isso, que alguma ação concreta se desencadeie para a transformação da prática pedagógica, alvo maior de todos os desafios da atual educação brasileira.

Recebido em: 04/11/2019

Aprovado em: 14/12/2019

\section{Notas}

1 Mestrado em Educação. Especialista em Língua Portuguesa, Psicanálise e Educação. Graduada em Letras. Professora há 36 anos, com experiência em docência e gestão pedagógica na Educação Básica e Superior. Autora de módulos de estudo em graduação na área de Leitura e Produção de Texto Acadêmico (LPTA), Metodologia do Ensino da Língua Portuguesa, Literatura Infantil, 
Docência no Ensino Superior e Metodologia da Pesquisa. Organizadora do documento de referência da área de linguagens e códigos para o Sistema Marista de Avaliação. Experiência de mais de uma década como orientadora de pesquisas em Instituições de Ensino Superior privadas do Distrito Federal. Como coordenadora pedagógica em Brasília, possui as seguintes experiências: coordenadora pedagógica de uma rede de escolas, na qual implantou o projeto de práticas de leitura, letramento e multiletramentos, intitulado "Ler para Ser"; coordenadora do Departamento de Letramento do Centro Universitário IESB; coordenadora pedagógica da Comissão de Implantação do Novo Ensino Médio em Tempo Integral da SEE-DF. Na gestão da educação, foi diretora da Educação de Jovens e Adultos da SEE-DF. Atualmente, é assessora pedagógica da Rede Salesiana Brasil de Escolas. E-mail: professoraleoneide@gmail.com

2 Pesquisa disponível em: http://acaoeducativa.org.br/wp-content/uploads/2018/08/ Inaf2018_Relat\%C3\%B3rio-Resultados-Preliminares_v08Ago2018.pdf

3 Pesquisa disponível em: https://www.cnm.org.br/index.php/comunicacao/noticias/estudantes-brasileiros-devem-demorar-mais-de-260-anos-para-atingir-qualidade-de-leitura-de-paises-desenvolvidos

\section{Referências}

BAGNO, Marcos. Linguística da norma. São Paulo: Edições Loyola, 2002. BORTONI-RICARDO, Stella Maris et al. (org.). Leitura e mediação pedagógica. São Paulo: Parábola, 2012.

BRASIL. Ministério da Educação (MEC). Conselho Nacional de Secretários de Educação (CONSED); União Nacional dos Dirigentes Municipais de Educação (UNDIME). Base Nacional Comum Curricular. Brasília: MEC, 2018.

BRITTOO, Luiz. Sociedade de cultura escrita, alfabetismo e participação. In: RIBEIRO, Vera Masagão (org.). Letramento no Brasil: reflexões a partir do INAF 2001. São Paulo: Global, 2003. p. 47-63.

CNM - Confederação Nacional de Municípios. Estudantes brasileiros devem demorar mais de 260 anos para atingir qualidade de leitura de países desenvolvidos. Brasília, 23 abr. 2018. Disponível em: https://www.cnm. org.br/index.php/comunicacao/noticias/estudantes-brasileiros-devem-demorar-mais-de-260-anos-para-atingir-qualidade-de-leitura-de-paises-desenvolvidos. Acesso em: 20 out. 2018.

DELORS, Jacques (coord.). Educação: um tesouro a descobrir. Relatório para a UNESCO da Comissão Internacional sobre Educação para o século XXI. São Paulo: Cortez; Brasília: UNESCO, MEC, 2010.

GADOT'TI, Moacir. Escola cidadã. São Paulo: Cortez, 2000.

KNELLER, George. Introdução à filosofia da educação. Rio de Janeiro: Ed. Zahar, 1972. 
KUENZER, Acácia Zeneida. As mudanças no mundo do trabalho e a educação: novos desafios para a gestão. In: FERREIRA, Naura (org.). Gestão democrática da educação: atuais tendências, novos desafios. 6. ed. São Paulo: Cortez, 2008. p. 33-58

LIMA, Ana; CATELLI JR., Roberto. INAF Brasil 2018: resultados preliminares. São Paulo: Instituto Paulo Montenegro, Ação Educativa, 2018. Disponível em: http:/ /acaoeducativa.org.br/wp-content/uploads/2018/08/Inaf2018_Relat $\%$ C3\%B3rio-Resultados-Preliminares_v08Ago2018.pdf . Acesso em: 20 out. 2019 .

RIBEIRO, Vera Masagão. Alfabetismo e atitudes: pesquisa junto a jovens e adultos paulistanos. Revista Brasileira de Educação, São Paulo, v. 9, n. 9, p. 5-15, 1998.

RIBEIRO, Vera Masagão (org.). Letramento no Brasil: reflexões a partir do INAF 2001. São Paulo: Global, 2003.

RODRIGUES, Cláudia Ribeiro. Por uma Pedagogia a serviço dos multiletramentos. Anais do Congresso Nacional Universidade, EAD e Software Livre, v. 1, n. 7, p. 1-4, 2016. Disponível em: http://www.periodicos.letras.ufmg. br/index.php/ueadsl/article/viewFile/11510/10070. Acesso em: 10 out. 2019.

ROJO, Roxane Helena Rodrigues. Pedagogia dos multiletramentos: diversidade cultural e de linguagens na escola. In: ROJO, Roxane Helena Rodrigues; MOURA, Eduardo (org.). Multiletramentos na escola. São Paulo: Parábola Editorial, 2012. p. 11-31.

SILVA, Themis Rondão Barbosa da Costa. Pedagogia dos multiletramentos: principais proposições metodológicas e pesquisas no âmbito nacional. Letras, Santa Maria, v. 26, n. 52, p. 11-23, jan./jun. 2016. Disponível em: https:// periodicos.ufsm.br/letras/article/viewFile/25319/14659. Acesso em: 10 out. 2019.

SOARES, Magda. Letramento: um tema em três gêneros. 2. ed. São Paulo: Autêntica, 2003. 